\title{
Improving Clinical Documentation through Monthly Audits in Butare Teaching Hospital, Rwandla
}

\author{
Joyce Kamanzi' ${ }^{1}$, Abraham Megentta ${ }^{2}$, Wilson Nsabiyumva1, Augustin Sendegeya1, \\ Rex Wong ${ }^{2}$ \\ ${ }^{1} \mathrm{CHUB}$, Butare, Rwanda \\ ${ }^{2}$ Yale Global Health Leadership Institute, Yale University, New Haven, USA \\ Email: rex.wong@yale.edu
}

Received 19 November 2015; accepted 13 December 2015; published 16 December 2015

Copyright (C) 2015 by authors and Scientific Research Publishing Inc.

This work is licensed under the Creative Commons Attribution International License (CC BY). http://creativecommons.org/licenses/by/4.0/

(c) (i) Open Access

\begin{abstract}
Creditable and timely clinical documentation is an essential component in patient care quality improvement. We designed and implemented a practical clinical audit process as a way of measuring and improving quality of clinical care in Rwanda; as well as to enhance the compliance score according to the hospital accreditation standards. The project took place at Central University Hospital in Butare (CHUB). A pre- and post-intervention study was used to examine the impact of creating a standardized auditing system on the department clinical auditing completion rate and the accreditation standards compliance rate. Once audit results are entered into the MS Excel tool created, the completion and accreditation compliance rate are automatically computed by the system. The results were presented in the monthly QI meeting as feedback. Two sets of measures were collected: 1) department clinical auditing completion rate, and 2) the COHSASA standards compliance rate. The completion rate of monthly audit reports increased from $57 \%$ (pre-intervention) to $\mathbf{9 6 \%}$ (post-intervention), $\mathrm{P}<\mathbf{0 . 0 0 0}$. The hospital-wide average accreditation standards compliance rate for clinical documentation also significantly improved from $27 \%$ to $60 \%, P=$ 0.000. Providing departments a simple and user-friendly clinical documentation auditing tool can enhance the completion rate of audit reporting at no additional cost to the hospital. Hospital leadership plays to support and organize the system are crucial. These data can be used for evidence-based decision making to improve completeness and accuracy of clinical documentation and thus comply with accreditation standards.
\end{abstract}

\section{Keywords}

Clinical Documentation, Accreditation, Resource-Limited Setting, Quality Improvement 


\section{Introduction}

Many low and mid income countries (LMIC) have focused on improving access to primary care for the last decades [1]. Initiatives like Last Mile from USAID DELIVER aim at improving the supply chain of medications and other health care products to remote places in many LMIC to ensure the availability of health products [2]-[6]. Efforts to increase community involvement in health promotion efforts by creating community health workers programs (CHW) were also adopted by many countries [7]-[12]. The CHW programs extend the reach of health systems and improve access to vulnerable and under-served populations [13]-[15]. Some countries also provide national health insurance systems to ensure their citizens have access to affordable health care [16]-[18].

Recently, attention has turned to improving the quality of medical and health care, particularly in African countries [19]. Many quality improvement initiatives have demonstrated positive results in resource limited settings [20]-[23]. Creditable and timely clinical documentation is an essential component in patient care quality improvement; not only validating the care that was provided, it also shares relevant clinical information between healthcare providers in order to make evidence-based healthcare decisions. Incomplete or non-credible document may result in communication failures that could result in harm to a patient [24]-[28]. Many efforts on improving clinical documentation completeness in recent years have been focusing on the effectiveness of electronic documentation systems and mostly were conducted in developed countries [29]-[31]. Study on improving clinical documentations in resource-limited settings, where paper-based documentation remains the norm, however, was less available.

Accordingly, we sought to design and implement a practical clinical audit process as a way of measuring and improving quality of clinical care in a LMIC hospital. The Ministry of Health of Rwanda has adopted many strategies to strengthen the country's health systems and to improve quality of care; one of such strategies is the Rwanda's Human Resources for Health (HRH) program [32]. Through the HRH program, health management mentors from United States partnered with Rwandese hospital staff to conduct this quality improvement project. This paper aims to describe the process the hospital has adopted in order to improve the clinical documentation auditing completion rate and enhance the compliance score according to the Council for Health Service Accreditation of Southern Africa (COHSASA) accreditation standards related to clinical documentation practices [33]. COHSASA was commissioned by Rwanda to accredit all the teaching hospitals in the country since 2006 [34].

\section{Methods}

\subsection{Setting}

The quality improvement project took place at Central University Hospital in Butare (CHUB), the only teaching Hospital in the Southern Province of Rwanda. It has 500 beds and receives referrals from 15 district hospitals. It has 23 clinical departments and units. In order to monitor clinical documentation practices and reflect the level of compliance with the COHSASA standards, all 23 clinical departments and units are required to produce monthly clinical documentation audit reports since 2013. The hospital, however, had no standardized or coordinated process for clinical documentation audit reporting; Information collected from the audits could not be analyzed and used to monitor and improve clinical documentation. In August 2014, the completion rate of monthly audit (defined as the percentage of all departments performed the audits) was 57\%, and the hospitalwide COHSASA score related to clinical documentation was $27 \%$. Since there was no routine audit reports, departments did not know their performance.

\subsection{Design}

We implemented a pre- and post-intervention study to examine the impact of creating a standardized auditing system on the department clinical auditing completion rate and the COHSASA standards compliance rate. All 23 clinical departments and units were included in this project.

Auditing completion rate was measured by the percentage of clinical departments which conducted clinical audit. Each month, each department is required to select and audit a minimum of 10 patient files from their department. The pre-intervention period included July through September of 2014. The post-intervention period included October 2014 through March 2015. 


\subsection{Intervention}

A working group was formed in August 2014 to address this issue. The team member included the head and staff from the Quality Improvement (QI) department of the hospital and health management mentors from the HRH program. The team worked closely on daily basis with the individual department heads and utilized a Strategic Problem Solving Approach [35] to identify the problem, set objective, and assess the root cause. During the assessment, the team found out a minimum of 10 patient files were randomly selected and audited monthly by each department; however, there was no standardized method for the departments to report their results. Consequently, individual departments would spend time and effort to conduct the audits and create reports yet their results between departments were not comparable. The team, after comparing different options, decided to create an MS Excel tool to address this issue based on the cost, feasibility, ease to use and potential sustainability. An auditing form was designed to facilitate the auditing process for each department. Each department developed a customized Clinical Audit Form (Appendix 1) based on the 45 COHSASA accreditation standards related to clinical documentation. The Form has five sections. Section A has 5 items related to the documentation standards of patient's particulars. Section B has 25 items related to documenting diagnosis and treatment. Sections C, D and E all have 5 items each related to information provided to patients, discharge/transfer information, and follow up, respectively.

Each section has assigned a weighed score based on their critical status according to the COHSASA criteria. Each audited item would be given a score of 2 for compliant (C), 1 for partial compliant (PC), and 0 for non-compliant (NC). Any item that is not applicable would be marked "NA" and would not be included in the score calculation. The section score is the combined score of all items multiplied by the weight; and the total score is the combined scores of all sections. The percentage of compliance is calculated using the total score divided by the highest possible score for the audit.

When individual departments completed their audits, their results were entered into the MS Excel tool. Once information is entered to the program, the completion rate as well as COHSASA standards compliance rate will be automatically computed. One half-day training session was provided to all staff assigned to participate in the audits to ensure they understand how to use the new tools and the team also provided one-on-one support to the individuals who needed more assistance.

Official implementation of the new system began in late September. Since the official implementation, the audit and compliance results of each department were presented in the monthly QI meeting as feedback to their performance. Using the results, actions to improve clinical documentation were discussed, agreed upon and taken back to the departments for implementation.

\subsection{Measures}

Two sets of measures were collected to evaluate this project: 1) department clinical auditing completion rate, and 2) the COHSASA standards compliance rate.

\subsection{Data Analysis}

McNemar test was conducted to compare the pre and post intervention department clinical auditing completion rate and Mann Whitney test was conducted to compare the pre and post intervention COHSASA standards compliance rates. Non-parametric tests were chosen since the probability distribution was not assumed. All statistical tests were done using SPSS at significant level at 0.05 .

\section{Results}

All 23 hospital departments took part in the monthly clinical documentation audits. The completion rate of monthly audit reports increased from 57\% (pre-intervention) to $96 \%$ (post-intervention), $\mathrm{P}<0.000 .287$ patient files were audited pre-intervention and 1193 patient files post-intervention. The hospital-wide average COHSASA standards compliance rate for clinical documentation also significantly improved from $27 \%$ to $60 \%, \mathrm{P}=0.000$ (Table 1).

\section{Discussion}

Our project significantly improved the clinical documentation audit completion rate and increased the COHSASA 
Table 1. Pre and post intervention of measures.

\begin{tabular}{ccccc}
\hline Measures & Pre-intervention & Post-intervention & Increase & P-value \\
\hline Department completion rate & $57 \%$ & $96 \%$ & $39 \%$ & $<0.001^{* *}$ \\
COHSASA compliance rate & $27 \%$ & $60 \%$ & $33 \%$ & $<0.001^{* *}$ \\
\hline
\end{tabular}

${ }^{* *}$ Statistically significant at $\mathrm{P}=0.05$.

compliance rate for clinical documentation. The two-month implementation preparation included assessment, planning, tool creation and training. Apart from human resources and time investment, the project bore no financial cost. Our project showed a well-designed quality improvement project can successfully improve clinical documentation compliance with little investment from the hospital.

The project addressed the clinical auditing issues utilized many quality improvement and leadership principles. A working team was formed to define and measure the problem, assessed the situation to identify root causes, create viable and cost effective interventions and implement change. The staff from within the hospital (Quality Improvement Department) took ownership of the project. Detailed assessment of the processes and situation analysis were used to understand the gaps of the current process, and the intervention created was simple and cost-effective.

The approval from the senior leadership of the hospital was critical to assure high-level support for the project. Clear and frequent communication is a core component in any successful quality improvement project. The senior management team was informed about the project from the beginning; their support is communicated to all the departments to ensure their understanding the purpose and importance of the project. The intervention selected was addressing the needs which were identified during assessment: 1) creating a standard system so comparison between department is feasible; 2 ) the computer system automatically generates pre-set reports once data entry is completed, the end users do not need to spend time in compiling reports. The system also helps eliminating human errors in creating reports; 3) an existing monthly QI meeting was leveraged as the forum for sharing the results and providing feedback. The meetings not only allow the departments to see their individual departments' performance, but also provide an environment for them to learn how to utilize the data they have collected to make decisions. All participants in the QI meeting can share their concerns, provide suggestions and seek advice from others on how to improve their clinical documentations.

The zero financial cost was critical to the project's feasibility and eventually sustainability. The intervention was selected to ensure it utilized the already existing resources available within the hospital. Utilizing the internal skills and expertise to create the auditing system not only saved money and allowed rapid implementation, it also ensures the hospital staff can resolve problems for other users in the hospital. Sufficient trainings were provided to all the end users to ensure they are competent in using the tools; the trainings also served as a forum to collect feedback from end users to modify the tool accordingly to meet their needs.

Despite the initial successes, our project has several limitations. First, our study was limited to a single organization; results may differ in other hospitals. Second, each department audit 10 patient files each month, the within-department sample size is small. Also, the number of patient files audited in each department should be adjusted according to the patient volume. Third, this project did not verify the self-assessed compliance score. The actual accreditation outcome would be available only after surveyed by the accreditation agency. Fourth, we could not assess long term sustainability and further follow-up is warranted.

This project demonstrates that quality improvement principles can help address accreditation issues in a resource-challenged setting. By focusing on process and utilizing internal capacity; the clinical audit completion rate and documentation compliance rate have increased considerably.

\section{Conclusion}

Providing departments a simple and user-friendly clinical documentation auditing tool can enhance the completion rate of audit reporting at no additional cost to the hospital. While the hospital senior leadership plays an important role in supporting the project, the hospital's QI Department can play a vital role in organizing a systematic method for auditing clinical documentation and providing feedback to department managers. These data can be used for evidence-based decision making to improve completeness and accuracy of clinical documentation and thus comply with accreditation standards. 


\section{References}

[1] Chakkalakal, R.J., Cherlin, E., Thompson, J., Lindfield, T., Lawson, R. and Bradley, E.H. (2013) Implementing Clinical Guidelines in Low-Income Settings: A Review of Literature. Global Public Health, 8, 784-795. http://dx.doi.org/10.1080/17441692.2013.815794

[2] (2015) USAID DELIVER Project. http://deliver.jsi.com/dhome/whatwedo/supplychainsys/scsyslastmile

[3] DELIVER (2011) Using Last Mile Distribution to Increase Access to Health Commodities. USAID, DELIVER PROJECT, Task Order 4. http://deliver.jsi.com/dlvr_content/resources/allpubs/guidelines/UsinLastMileDist.pdf

[4] Bunde, E., Kajawu, L., Marufu, C. and Alt, D. (2007) Zimbabwe: Delivery Team Topping Up (DTTU) System Assessment. USAID, DELIVER PROJECT, Task Order 1, Arlington.

[5] DELIVER (2007) Zimbabwe: Final Country Report. DELIVER, for the U.S. Agency for International Development, Arlington. http://deliver.jsi.com/dlvr_content/resources/allpubs/policypapers/DELIVER_FinalProjectReport.pdf

[6] Hasselberg, E. and Byington, J. (2010) Supply Chain Models and Considerations for Community-Based Distribution Programs: A Program Manager’s Guide. Reproductive Health Supplies Coalition, Arlington.

[7] Earth Institute (2011) One Million Community Health Workers. Task Force Report. Columbia University, New York.

[8] Tulenko, K., Mogedal, S., Afzal, M., et al. (2013) Community Health Workers for Universal Health-Care Coverage: From Fragmentation to Synergy. Bulletin of the World Health Organization, 9, 847-852. http://dx.doi.org/10.2471/BLT.13.118745

[9] Global Health Workforce Alliance (GHWA) (2010) Integrating Community Health Workers in National Health Workforce Plans. WHO, Geneva.

[10] Singh, P. and Sachs, J. (2013) 1 Million Community Health Workers in Sub-Saharan Africa by 2015. Lancet, 382, 363-365. http://dx.doi.org/10.1016/S0140-6736(12)62002-9

[11] Haines, A., Sanders, D., Lehmann, U., Rowe, A., Lawn, J., Jan, S., et al. (2007) Achieving Child Survival Goals: Potential Contribution of Community Health Workers. Lancet, 369, 2121-2131. http://dx.doi.org/10.1016/S0140-6736(07)60325-0

[12] Global Health Workforce Alliance and World Health Organization (2014) A Universal Truth: No Health without a Workforce. WHO, Geneva.

[13] Naimoli, J.F., Perry, H.B., Townsend, J.W., Frymus, D.E. and McCaffery, J.A. (2015) Strategic Partnering to Improve Community Health Worker Programming and Performance: Features of a Community-Health System Integrated Approach. Human Resources for Health, 13, 46. http://www.human-resources-health.com/content/pdf/s12960-015-0041-3.pdf http://dx.doi.org/10.1186/s12960-015-0041-3

[14] Christopher, J., Le, M., Lewin, S. and Ross, D. (2011) Thirty Years after Alma-Ata: A Systematic Review of the Impact of Community Health Workers Delivering Curative Interventions against Malaria, Pneumonia and Diarrhoea on Child Mortality and Morbidity in Sub-Saharan Africa. Human Resources for Health, 9, 27. http://dx.doi.org/10.1186/1478-4491-9-27

[15] Swider, S. (2002) Outcome Effectiveness of Community Health Workers: An Integrative Literature Review. Public Health Nursing, 19, 11-20. http://dx.doi.org/10.1046/j.1525-1446.2002.19003.x

[16] Government of Nepal, Department of Health Services (2013) National Health Insurance Policy. GoN/DoHS, Kathmandu.

[17] Dalinjong, P.A. and Laar, A.S. (2012) The National Health Insurance Scheme: Perceptions and Experiences of Health Care Providers and Clients in Two Districts of Ghana. Health Economics Review, 2, 13. http://dx.doi.org/10.1186/2191-1991-2-13

[18] Lagomarsino, G., Garabrant, A., Adyas, A., Muga, R. and Otoo, N. (2012) Moving towards Universal Health Coverage: Health Insurance Reforms in Ninedeveloping Countries in Africa and Asia. Lancet, 380, 933-943. http://dx.doi.org/10.1016/S0140-6736(12)61147-7

[19] WHO (2003) Quality and Accreditation in Health Care Services: A Global Review. Evidence, Geneva.

[20] Byiringiro, J.C., Wong, R., Davis, C., Williams, J., Becker, J., Novik, J., Uwineza, C., Mukakamali, C.D., Hategekimana, T. and Nyundo, M. (2015) Applying Quality Improvement Principles to Improve Accident and Emergency Department Overcrowding and Flow in Rwanda: A Case Study. Journal of Hospital Administration, 4, 47-51. http://dx.doi.org/10.5430/jha.v4n5p47

[21] Campbell, H., Duke, T., Weber, M., English, M., Carai, S. and Tamburlini, G. (2008) Global Initiatives for Improving Hospital Care for Children: State of the Art and Future Prospects. Pediatrics, 121, 984-992. http://dx.doi.org/10.1542/peds.2007-1395 
[22] Berwick, D.M. (2004) Lessons from Developing Nations on Improving Health Care. British Medical Journal, 328, 1124-1129. http://dx.doi.org/10.1136/bmj.328.7448.1124

[23] Bradley, E., Hartwig, K.A., Rowe, L.A., Cherlin, E.J., Pashman, J., Wong, R., et al. (2008) Hospital Quality Improvement in Ethiopia: A Partnership-Mentoring Model. International Journal of Quality Health Care, 20, 392-399. http://dx.doi.org/10.1093/intqhc/mzn042

[24] Boone, K.W. (2011) The CDA 9 TM Book. Springer-Verlag, London. http://dx.doi.org/10.1007/978-0-85729-336-7

[25] Towers, A.L. (2013) Clinical Documentation Improvement-A Physician Perspective. Journal of AHIMA, 84, 34-41.

[26] D’Amore, J.D., Sittig, D.F., Wright, A., Iyengar, M., Sriram, N. and Roberta, B. (2011) The Promise of the CCD: Challenges and Opportunity for Quality Improvement and Population Health. AMIA Annual Symposium Proceedings, 2011, 285-294.

[27] D’Amore, J.D., Sittig, D.F. and Ness, R.B. (2012) How the Continuity of Care Document Can Advance Medical Research and Public Health. American Journal of Public Health, 102, e1-e4. http://dx.doi.org/10.2105/AJPH.2011.300640

[28] Ferranti, J.M., Musser, R.C., Kawamoto, K. and Hammond, W.D. (2006) The Clinical Document Architecture and the Continuity of Care Record: A Critical Analysis. Journal of the American Medical Informatics Association, 13, $245-252$. http://dx.doi.org/10.1197/jamia.M1963

[29] Cebul, R.D. (2011) Electronic Health Records and Quality of Diabetes. The New England Journal of Medicine, 365, 2338-2339. http://dx.doi.org/10.1056/NEJMc1111722

[30] Park, S.Y. (2012) The Effects of EMR Deployment on Doctors’ Work Practices: A Qualitative Study in the Emergency Department of a Teaching Hospital. International Journal of Medical Informatics, 81, 204-217. http://dx.doi.org/10.1016/j.ijmedinf.2011.12.001

[31] Mitsch, C., Huber, P., Kriechbaum, K., Scholda, C., Duftschmid, G., Wrba, T. and Schmidt-Erfurth, U. (2015) Impact of Electronic Health Records on the Completeness of Clinical Documentation Generated during Diabetic Retinopathy Consultations. Applied Clinical Informatics, 6, 478-487. http://dx.doi.org/10.4338/ACI-2015-03-RA-0028

[32] Binagwaho, A., Kyamanywa, P., Farmer, P.E., Nuthulaganti, T., Umubyeyi, B., Nyemazi, J.P., et al. (2013) The Human Resources for Health Program in Rwanda-New Partnership. The New England Journal of Medicine, 369, 20542059. http://dx.doi.org/10.1056/NEJMsr1302176

[33] COHSASA. Accessed on June 2015. http://www.cohsasa.co.za

[34] Ministry of Health (2014) Rwanda Hospital Accreditation Standards. Second Edition.

[35] Banaszak-Holl, J., Nembhard, I., Taylor, L. and Bradley, E.H. (2012) Cengage Learning, Chapter 2. Leadership and Management: A Framework for Action. 


\section{Appendix 1. Clinical Documentation Auditing Form}

Current date:

Department:

Patient number:

Admission date:

Diagnosis:

\begin{tabular}{|c|c|c|c|c|c|c|c|}
\hline A. & PATIENT'S DETAILS (on each page) & $\mathrm{NC}=0$ & $\mathrm{PC}=1$ & $C=2$ & NA & COMMENTS & 15 \\
\hline 1. & Name-Initials & & & & & & \\
\hline 2. & Age/DoB & & & & & & \\
\hline 3 & Hospital number & & & & & & \\
\hline 4. & Ward or Outpatient Department & & & & & & \\
\hline 5. & The responsible doctor is identified on each page & & & & & & \\
\hline B. & DOCUMENTATION & $\mathrm{NC}=0$ & $\mathrm{PC}=1$ & $C=2$ & NA & COMMENTS & 150 \\
\hline 1. & $\begin{array}{l}\text { All appropriate patient details are recorded on admission form or } \\
\text { outpatient registration }\end{array}$ & & & & & & \\
\hline 2. & Time of Admission to ward or outpatient department is recorded & & & & & & \\
\hline 3. & Date \& time of first consultation on ward outpatient clinic is recorded & & & & & & \\
\hline 4. & First consultation is within the expected time frame & & & & & & \\
\hline 5. & Medical history, including psychosocial history & & & & & & \\
\hline 6. & Medical examination & & & & & & \\
\hline 7. & Patient allergies and risk factors are clearly identified & & & & & & \\
\hline 8. & Details of medical findings leading to a diagnosis are recorded & & & & & & \\
\hline 9. & Requests for diagnostic tests & & & & & & \\
\hline 10. & Results of diagnostic tests & & & & & & \\
\hline 11. & Drs' signature on results of investigations & & & & & & \\
\hline 12. & Medical treatment prescribed, in notes and on prescription sheets & & & & & & \\
\hline 13. & Prescription sheet is correctly completed & & & & & & \\
\hline 14. & Record of every consultation is evident & & & & & & \\
\hline 15. & $\begin{array}{l}\text { The admission nursing assessment is completed within the required time } \\
\text { frame }\end{array}$ & & & & & & \\
\hline 16. & $\begin{array}{l}\text { Record of consultation with other clinical support services: Physio, social } \\
\text { worker, etc. }\end{array}$ & & & & & & \\
\hline 17. & All entries are labelled, e.g. "Doctor's Note” & & & & & & \\
\hline 18. & Each entry is dated, timed and in chronological order & & & & & & \\
\hline 19. & Entries are legible & & & & & & \\
\hline 20. & Only approved abbreviations are used & & & & & & \\
\hline 21. & Nutritional needs are detailed as required & & & & & & \\
\hline 22. & Legible signature and status included on every entry & & & & & & \\
\hline 23. & Referral letters and degree of urgency (Internal only) & & & & & & \\
\hline 24. & Interdisciplinary communication is documented & & & & & & \\
\hline 25. & All nursing charts are correctly completed & & & & & & \\
\hline C. & INFORMATION FOR PATIENTS & $\mathrm{NC}=0$ & $\mathrm{PC}=1$ & $C=2$ & NA & COMMENTS & 25 \\
\hline 1. & Patient and/or carer are fully informed of findings & & & & & & \\
\hline 2. & Patient and/or carer is aware of appropriate options for treatment & & & & & & \\
\hline 3. & Patient and/or Carer participated in decision-making relating to treatment & & & & & & \\
\hline 4. & Patient education is documented & & & & & & \\
\hline 5. & Informed consent was sought and given for interventional procedures & & & & & & \\
\hline
\end{tabular}




\section{Continued}

\begin{tabular}{|c|c|c|c|c|c|c|c|}
\hline D. & DISCHARGE/TRANSFER OF PATIENTS & $\mathrm{NC}=0$ & $\mathrm{PC}=1$ & $C=2$ & NA & COMMENTS & 25 \\
\hline 1. & There is evidence of discharge or outpatient follow-up planning & & & & & & \\
\hline 2. & $\begin{array}{l}\text { Follow-up arrangements are agreed with patients and carers by doctors } \\
\text { prior to discharge or outpatient procedure/ treatment has been completed }\end{array}$ & & & & & & \\
\hline 3. & $\begin{array}{l}\text { Discharge or outpatient treatment follow-up summary in Patient's clinical } \\
\text { file or a short summary in out-patient note is evident }\end{array}$ & & & & & & \\
\hline 4. & Referral letter to community doctor if required & & & & & & \\
\hline 5. & $\begin{array}{l}\text { Education, re: discharge or post-outpatient procedure/ treatment drugs, is } \\
\text { noted }\end{array}$ & & & & & & \\
\hline E. & GENERAL OVERVIEW & $\mathrm{NC}=0$ & $\mathrm{PC}=1$ & $C=2$ & NA & COMMENTS & 15 \\
\hline 1. & The clinical record reflects a high quality of care & & & & & & \\
\hline 2. & Presents a total picture of this patient & & & & & & \\
\hline 3. & $\begin{array}{l}\text { The clinical record reflects the involvement of other healthcare team } \\
\text { members e.g. Social Worker, etc. }\end{array}$ & & & & & & \\
\hline 4. & There is evidence that hospital policies were followed & & & & & & \\
\hline 5. & $\begin{array}{l}\text { Patient education during hospitalisation or outpatient consultation/ } \\
\text { procedure/ treatment, and at discharge or outpatient follow-up planning } \\
\text { were adequate }\end{array}$ & & & & & & \\
\hline
\end{tabular}

AUDITORS NAME:

SIGNATURE:

\section{COMMENTS/CONCLUSION/FEEDBACK:}

\section{OUTCOME OF AUDIT}

Reported to:

Reported by:

Date:

\begin{tabular}{|c|c|c|c|c|c|c|}
\hline Section & Section score & & Weigh & & Compliance rate ${ }^{*}$ & \\
\hline A & & $\mathrm{X}$ & 1.5 & $=$ & & $/ 15$ \\
\hline $\mathrm{B}$ & & $\mathrm{X}$ & 3 & $=$ & & $/ 150$ \\
\hline $\mathrm{C}$ & & $\mathrm{X}$ & 2.5 & $=$ & & $/ 25$ \\
\hline $\mathrm{D}$ & & $\mathrm{X}$ & 2.5 & $=$ & & $/ 25$ \\
\hline $\mathrm{E}$ & & $\mathrm{X}$ & 1.5 & $=$ & & $/ 15$ \\
\hline Total & & & & $=$ & & $/ 230$ \\
\hline
\end{tabular}

"The max expected score may change if any item within the section is marked "NA" 